\title{
Measuring hope: validity of short versions of four popular hope scales
}

\author{
Emma Pleeging ${ }^{1}$
}

Accepted: 5 January 2022 / Published online: 27 January 2022

(c) The Author(s) 2022

\begin{abstract}
Popular hope-instruments differ significantly in how they define hope. Due to their length, these instruments are rarely used in large-scale surveys or combined in interdisciplinary research. This study validates short versions of four hope instruments; the Adult Trait Hope Scale; Herth Hope Index; Locus Of Hope Scale; and spiritual dimension of the Comprehensive Hope Scale. Results show that the short versions function equally well as their longer counterparts. However, all scales show remarkably low correlations with similar concepts such as a single-item-hope-question and expectations. We argue that hope is a multi-dimensional phenomenon and that each of these instrument covers only one part of the experience, meaning that combining these instruments would yield more comprehensive insights. Moreover, cross-cultural comparison indicates that the social LOHS and spiritual CHS are less important in the Netherlands compared to Mexico. These findings suggest that different instruments might be more relevant in different contexts.
\end{abstract}

Keywords Hope $\cdot$ Interdisciplinary $\cdot$ Instrument $\cdot$ Hope index $\cdot$ Short scale

\section{Introduction}

Over the past decades, hope has increasingly become a topic of interest in several scientific disciplines, such as psychology, health science, economics and anthropology (Van den Heuvel 2020). This is perhaps not very surprising, considering the relatively large impact that hope appears to have on our daily lives. Research has found hope to be an important correlate or determinant of several, mainly positive, life-outcomes such as the academic and athletic success of youngsters (Snyder 2002); recovery after (mental) illness (Snyder 2002; Herth 1992); proactive economic behaviour (Duflo 2012; Reichard et al. 2013; Flechtner 2014; Lybbert and Wydick 2018); sustainable behaviour (Ojala 2012; Pleeging et al. 2020); mental health and even longevity (Graham and Pinto 2019; O'Connor and Graham 2019). However, research on the topic has remained largely within the confines of these different disciplines, meaning that the specific definition and instruments used to measure hope are often quite divergent between

Emma Pleeging

pleeging@ese.eur.nl

1 Erasmus Happiness Economics Research Organisation, Erasmus University Rotterdam, Burgermeester Oudlaan 50, 3000 DR Rotterdam, The Netherlands 
fields (Bailey et al. 2007; Webb 2007; Redlich-Amirav et al. 2018; Pleeging et al. 2021b). While studies within psychology for example predominantly make use of the Adult Trait Hope Scale (ATHS), defining hope as a combination of agency and resourcefulness (Snyder et al. 1991); studies within health sciences usually perceive hope as the multidimensional experience of a confident, but uncertain expectation that is measured with the Herth Hope Index (HHI) (Herth 1992); whereas economic and sociological studies more often use existing, largescale datasets in which hope is generally understood as positive expectation (Graham and Pinto 2019; O'Connor and Graham 2019).

Although there is clearly some overlap between these approaches, there are also important differences. While the ATHS for example focuses on the agentic, behavioural domain of hope, the HHI is much more concerned with emotions and attitudes; and whereas the HHI perceives uncertainty as a defining trait of hope, expectations are generally centred on feelings of certainty (Bailey et al. 2007). Also, critique has been offered that most western instruments are focused too much on the individual, at the expense of a more social understanding of hope (Aspinwall and Leaf 2002; Bernardo 2010; Du and King 2013; Howell et al. 2015), as well as disregarding the more transcendental or spiritual components of the experience (Ludema et al. 1997; Scioli et al. 2011).

Building on the idea that hope entails multiple dimensions, such as cognitive, emotional, active and social traits, which each play a more or less important role in different contexts and therefore in different disciplines (Webb 2007), we assert that trans-disciplinary research and collaboration between disciplines is important to increase our understanding of hope in practical contexts. Such trans-disciplinary research relies on short, easy-to-use instruments, focusing on different domains of a hopeful experience. However, current instruments developed to measure hope are generally quite lengthy and can therefore not be easily added to or combined in empirical studies. The HHI and ATHS for example both consist of 12 items. Moreover, relatively little is known about how these different instruments relate to each other. In this study we therefore compare the original and brief versions of four popular hope-instruments, each covering a different domain of the hopeful experience, using three-wave panel data from a representative sample of around 1000 citizens from the Netherlands. The instruments studied are the HHI; ATHS; Locus of Hope Scale (LOHS); and spiritual dimension of the Comprehensive Hope Scale (CHS). We study the validity of shorter versions of each of these instruments and investigate how they compare to a single-item hope question and several related concepts, such as expectations, life satisfaction and positive affect.

This study has both relevance in practice and in the academic field. First, by validating brief versions of several well-known instruments, as well as the validity of a single-item hopequestion, we improve the possibility to study hope using less time-consuming methods, for example in larger-scale studies in which there is little room for long multi-item scales. Second, by examining how different hope-instruments are related, this study helps us estimate to what degree insights from one field are applicable in another. Third, by developing short, easy-to use hope-scales, it will hopefully become easier and more common to study hope in specific, societally relevant contexts, such as within organisations or municipalities. 


\section{Literature}

\subsection{Modes of hoping}

There are many different approaches to defining hope. In its simplest sense, we can turn to the 'orthodox definition', a very trimmed down definition of hope, developed and used mainly in the field of philosophy, which states that hope comprises two necessary and sufficient elements: a desire for an uncertain event (Day 1969; Martin 2011). When we hope for something, we express that we want this event to happen, but that we are never certain that it will, although we do think it is possible. Beyond this very brief definition, many more complex descriptions have been offered throughout the years, each with its own focus, be it on goal-achievement, the social context of hope, hope as an emotion or the prudence of hope. We assume here that these different definitions are not necessarily at odds with each other, but that there are multiple 'modes of hoping' (Webb 2007) that all reflect important components of hope and become more or less important depending on the specific context. "We may each of us at different times and in different circumstances experience hope in the manner described by Marcel or Dauenhauer or Bloch or Snyder or Rorty. Our hopes may be active or passive, patient or critical, private or collective, grounded in the evidence or resolute in spite of it, socially conservative or socially transformative. We all hope, but we experience this most human of all mental feelings in a variety of modes." (Webb 2007:80). Moreover, since each scientific discipline focuses on a specific part of reality, it is logical that their definition of hope is tailored to this context and might miss other components.

\subsection{Perspectives of hope}

In this study, we focus on four different hope-scales, which are, we argue, representative of four specific domains or perspectives of hope, namely hope as a cognitive (ATHS), emotional (HHI), social (LOHS) or spiritual (CHS) experience. Here, we take each instrument to cover one specific hope-domain, meaning that taken together, they cover a more substantial understanding of hope as a multi-dimensional phenomenon.

There are several reasons for choosing these specific scales. First, as these four scales are all previously validated and are already prevalent in existing empirical research, they have a better chance of proving to be useful in shortened versions. Moreover, we assume that each of these approaches adds something different to our understanding of hope, and is complementary to the others. Although there is some overlap, we will argue that each represents a distinct domain of hope, i.e. cognition, emotion, social hope or spirituality.

\subsubsection{Cognition-the ATHS}

In scientific research, especially within the field of psychology, Snyder's hope theory has been very influential in the past decades. This theory defines hope as a predominantly cognitive experience (Snyder 2002). According to this theory, hope is a combined sense of agency, or belief in our ability to reach our goals and a resourcefulness in following different pathways towards these goals even when we are met with obstacles. Snyder regards hope as "primarily a way of thinking, with feelings playing an important, albeit contributory role" (2002:249). In this theory, emotions function as feedback on how well we perceive we are doing in achieving our goals, yet the central experience of hope is defined as the thoughts we have about our abilities of goal-attainment. So, here hope is about the 
cognitive belief we can reach our goals, and emotions are viewed as sequela, i.e. consequences of these thoughts (Rand and Cheavens 2009). The related ATHS (Snyder et al. 1991) aims to capture the cognitive beliefs regarding goal achievement and comprises two dimensions; agency and pathways.

\subsubsection{Emotion-the Herth hope scale}

Perceptions of hope as an emotion are represented in many different theories over the past years. Fredrickson (2013) for example regards hope as one of the most common positive emotions that builds resilience and broadens our mindset, by motivating and encouraging people towards a brighter future. Also, often in response to the focus of Snyder's hope theory on cognition, several thinkers have argued that emotions play the most important role in the hopeful experience, for example in helping people decide what goals to pursue, whether to maintain or pause their actions, and as the overall hard-to-control 'feeling tone' that hope encompasses (Aspinwall and Leaf 2002; Scioli et al. 2011). In the often-used hope theory developed by Herth (1992), hope is defined as "a multi-dimensional dynamic life force characterized by a confident yet uncertain expectation of achieving good, which to the hoping person, is realistically possible and personally significant" (Herth 1992:1253). This approach defines three factors to hope, namely temporality and future, positive readiness and expectancy, and interconnectedness. Here, emotion plays an important role as the motivating force that results from perceiving a future goal as achievable. The HHI has been developed with these three domains in mind.

\subsubsection{Social hope-the locus of hope scale}

Hope can feel like a highly individual experience, since it involves our personal desires and estimations of achievement. Yet, to varying degrees, hope is also social. First, other people can be the source of our hopes; for example, by offering support, friendship, and a shared structure of norms and values, others can greatly influence both what we desire and what we believe we can achieve (Bernardo 2010; Du and King 2013). Second, other people can be the object of our hopes; in many cases, the things we hope for are not for ourselves, but for others (e.g. for our children to be happy) or are aimed at our relationships (e.g. to have a happy marriage) (Howell et al. 2015; Krafft and Walker 2018). Third, developing our hopes can be part of a social or even societal process, for example through a dialogue on what we find worthwhile and achievable (Ludema et al. 1997; Webb 2007; Scioli et al. 2011). The first of these is measured using the LOHS, which asks to what degree people's feelings of hope originate from others and to what degree they feel others help them achieve their goals ${ }^{1}$ (Bernardo 2010).

\subsubsection{Spirituality—the comprehensive hope scale}

Having hope can often be a transcendental or spiritual experience. First, since hope always involves some 'leap of faith' or trust in an unknown, it requires people to tap into their personal faith system about how they think the world works and what gives their life meaning

\footnotetext{
1 It is thus important to note that this instrument does not measure the social domain of hope, when it comes to others as the object or subject of our hopes.
} 
(Scioli et al. 2011). Such a system can be based on religion, but this does not have to be so; it can for example also be derived from trust in science or belief in fundamental human rights. Second, since humans are fundamentally hopeful beings, in the sense that we are always pulled forward, always act in accordance with a grounding belief that things can be better, hope can often comprise an existential or transcendental experience in itself (Marcel 1962; Ludema et al. 1997). The CHS (Scioli et al. 2011) covers four domains, namely an attachment, mastery, survival and spiritual domain. The spiritual component measures both spirituality as a source of hope, as well as hope as an inherently transcendental experience.

\section{Methodology}

\subsection{Participants}

For this study, three-wave panel was collected in the Netherlands in 2018, 2019 and 2020, through the Longitudinal Internet Studies for the Social sciences (LISS) panel, consisting of a true probability sample of households drawn from the population register by Statistic Netherlands. Overall, 903, 868 and 1261 respondents filled out the survey in the first, second and third wave. Due to attrition, the sample declined over the years, ${ }^{2}$ but was supplemented with new respondents from the same population each year. Results from wave 3 , in 2020, are used for all the analyses using cross-sectional data, as this is the most recent data and largest sample. As can be found in Table 1, the sample is largely representative of the population. Descriptives for the sample in 2018 and 2019 can be found in Appendix 2. For each of the scales, about $20 \%$ of the sample filled out the existing long versions, ${ }^{3}$ whereas the rest of the sample got the short version. Moreover, to assess cross-cultural reliability, a cross-sectional survey was conducted in the same year as wave two, among 244 English-speaking respondents from Mexico, using Prolific, a platform for academic survey-research. Descriptives of this sample can be found in Appendix 4.

\subsection{Materials}

\subsubsection{Demographics}

Respondents reported their age, gender, employment status, educational level, household composition, income and ethnicity. These characteristics were included as covariates in some of the analyses. Demographics for the sample can be found in Table 1.

\subsubsection{Hope scales}

Four original, previously validated hope scales were selected, each with their own specific focus on a part of hope. All the items to each of the hope-instruments used in this study can be found in Appendix 1.

\footnotetext{
${ }^{2}$ In each of the tables presenting the results, the exact number of observations used is mentioned.

3 A smaller group filled out the spiritual CHS, since this question contained a screening questions asking respondents whether they had any religious or non-religious spiritual beliefs or experiences. If respondents answered 'Not at all' they were not asked to fill out the CHS items.
} 
Table 1 Demographic characteristics of the sample

\begin{tabular}{|c|c|c|c|}
\hline & \multicolumn{2}{|c|}{ Sample } & Dutch average \\
\hline $\mathrm{N}$ & \multicolumn{2}{|l|}{1261} & \\
\hline Age (mean in years) & \multicolumn{2}{|l|}{55} & 42 \\
\hline \multicolumn{4}{|l|}{ Gender } \\
\hline Male & 592 & $47 \%$ & $50 \%$ \\
\hline Female & 669 & $53 \%$ & $51 \%$ \\
\hline \multicolumn{4}{|l|}{ Employment status } \\
\hline Employed & 507 & $45 \%$ & $51 \%$ \\
\hline Freelance & 58 & $7 \%$ & $2 \%$ \\
\hline Unemployed/unable to work & 89 & $31 \%$ & $20 \%$ \\
\hline Pensioned & 387 & $17 \%$ & $18 \%$ \\
\hline Other & 220 & & \\
\hline \multicolumn{4}{|l|}{ Education } \\
\hline Lower education & 292 & $24 \%$ & $33 \%$ \\
\hline Middle education & 431 & $34 \%$ & $40 \%$ \\
\hline Higher education & 482 & $38 \%$ & $27 \%$ \\
\hline Other $^{\mathrm{a}}$ & 56 & $4 \%$ & \\
\hline \multicolumn{4}{|l|}{ Household type } \\
\hline Single & 308 & $24 \%$ & $37 \%$ \\
\hline Partner, no children & 508 & $40 \%$ & $29 \%$ \\
\hline Partner and child(ren) & 350 & $28 \%$ & $27 \%$ \\
\hline Single with child(ren) & 61 & $5 \%$ & $7 \%$ \\
\hline Other & 34 & $3 \%$ & \\
\hline \multicolumn{4}{|l|}{ Income } \\
\hline$<€ 900$ & 29 & $3 \%$ & $5 \%$ \\
\hline$€ 900-1800$ & 193 & $17 \%$ & $38 \%$ \\
\hline$€ 1800-3200$ & 404 & $35 \%$ & $38 \%$ \\
\hline$€ 3200-5000$ & 334 & $29 \%$ & $17 \%$ \\
\hline$>€ 5000$ & 182 & $16 \%$ & $4 \%$ \\
\hline \multicolumn{4}{|l|}{ Ethnicity } \\
\hline Autochthonous & 1025 & $83 \%$ & $77 \%$ \\
\hline Western immigrant & 114 & $9 \%$ & $10 \%$ \\
\hline Non-western immigrant & 96 & $8 \%$ & $13 \%$ \\
\hline \multicolumn{4}{|l|}{ Long scales } \\
\hline ATHS & 259 & $21 \%$ & \\
\hline HHI & 260 & $21 \%$ & \\
\hline LOHS & 258 & $20 \%$ & \\
\hline CHS & 243 & $19 \%$ & \\
\hline No long scale & 241 & $19 \%$ & \\
\hline
\end{tabular}

${ }^{\mathrm{a}}$ This category comprises of respondents who have not (yet) finished any education or completed education outside of the common Dutch education system 
The Adult Trait Hope Scale (ATHS) developed by Snyder and colleagues (Snyder et al. 1991 ) is a 12-item Likert-type scale, of which 4 items are fillers, 4 are representative of the domain agency, i.e. the conviction that we can achieve our goals, and 4 items represent the domain pathways, i.e. the perceived resourcefulness in coming up with different ways to achieve someone's goals. Example statements are "I meet the goals that I set for myself" and "There are lots of ways around any problem", which are rated on a 7-point answering scale ranging from 'Completely disagree' to 'Completely agree'.

The Herth Hope Index (HHI) developed by Herth (1992) is an abbreviated, 12-item version of the Likert-type Herth Hope Scale, and aims to measure hope as "a multi-dimensional dynamic life force characterized by a confident yet uncertain expectation of achieving good, which to the hoping person, is realistically possible and personally significant" (Herth 1992:1253). It comprises three dimensions, namely temporality, i.e. someone's assessment of the future, positive readiness and expectancy, i.e. the behavioural and affective component, and interconnectedness, i.e. the relation to self and others that helps us feel hopeful. Sample items from the HHI include "I have inner positive energy", "I feel scared about my future" and "I feel overwhelmed and trapped" (last two reverse-scored).

The Locus Of Hope Scale (LOHS) builds on the ATHS and measures "whether the components of trait hope involve internal or external agents and internally or externally generated pathways" (Bernardo 2010:945). Similar to the ATHS, the LOHS comprises of two domains; agency and pathways. The original scale differentiates between an internal, personal locus of hope and an external locus of hope based on three sources, namely peers, family and a spiritual source. For brevity, in the current study we have combined all external sources to one, referring to the more generic term of 'others' as representative of an external locus of hope. Sample items include "I have reached many of my own goals with the help of others" and "Others can often help me think of different ways to get out of a jam".

The Comprehensive Hope Scale (CHS) is based on a multidisciplinary theory, defining hope as "a future-directed, four-channel emotion network [comprising] four constituent channels [of] mastery, attachment, survival, and spiritual systems" (Scioli et al. 2011:79). Here, we are specifically interested in the domain of spirituality, as the CHS is one of only a few instruments comprising questions to specifically measure spiritual hope. This part of the CHS comprises of 12 items, and sample items include "Spiritual beliefs provide me a sense of security" and "My spiritual beliefs are a source of comfort". Since the Netherlands is a highly secularized society, we opted to add a pre-screening question to the CHS, asking respondents whether they adhered to any religious or non-religious spiritual believes on a scale of 1 (Not at all) to 7 (Very much). Respondents who answered that they had no spiritual beliefs whatsoever, were not presented with the CHS-items.

\subsubsection{Convergent variables}

To measure convergent validity, several measures are included for which we expect a positive correlation. A single-item hope question asked respondents to indicate to what degree they had felt hopeful in the past four weeks, ranging from 1 (Never) to 7 (Always). Life satisfaction is measured using a single-item question which asked respondents how satisfied they are with their life as a whole, ranging from 0 (very dissatisfied) to 10 (very satisfied) (Cheung and Lucas 2014). Positive affect is assessed using the positive emotions from the short version of the Positive and Negative Affect Schedule (PANAS; see Watson et al. 
1988). This scale represents the balance of positive and negative emotions that participants experienced in the past month and scores range from 1 (Only negative emotions) to 7 (Only positive emotions). In this study respondents were asked about their expectations for several personal and societal matters, such as their household finances, the economy, education, safety and the climate. Health is measured by asking respondents to rate their health from 1 (very bad) to 5 (very good).

\subsection{Method and analyses}

In advance to this study, all instruments were translated to Dutch by a Dutch research team, all fluent in English. ${ }^{4}$ Also, before the main study, a pilot-study was conducted in another survey among 1,623 Dutch citizens, in an aim to select four items for each of the short versions of the ATHS, HHI, LOHS, and spiritual dimension of the CHS (descriptives of this sample can be found in Appendix 2 and results are reported in Sect. 4.1). In the main study, the long version of each of the hope scales was given to a randomly assigned group of about $20 \%$ of the total sample (see Table 1), while the rest of the respondents filled out the short version. The 'long-version groups' filled out the same long versions each year on top of the shorter versions of the other scales. ${ }^{5}$ In the analyses, the sample is divided between a 'long' and 'short' group.

Several statistical tests are performed to investigate the validity and reliability of the hope-instruments. Parallel reliability is estimated using pairwise correlations between the short and long versions of the hope scales. To test internal consistency, a Cronbach's alpha is calculated for each scale, measuring the how closely the items of each scale are related to each other. Test-retest reliability is estimated by calculating individual one-way randomeffects intraclass correlation coefficients (ICC) over the three years. Convergent validity is investigated by analysing pairwise correlations between hope and several states which we expect to be positively related to hope, namely a single-item hope question, life satisfaction, positive affect and expectations. To see whether these instruments measure pretty much the same thing or represent distinct parts of the hopeful experience, divergent validity is calculated by correlating the hope scales with each other. Factor analysis is used to study to what degree the short scales cover the subscales similarly to the longer scales. Then, hypothesis testing is done using all three waves of panel-data, by estimating a fixedeffects regression model relating hope to income, health and gender. Last, cross-cultural validity is studied by comparing results from the Dutch sample to a Mexican sample when it comes to mean scores, internal validity and convergent validity.

\section{Results}

\subsection{Item selection}

Item selection was based on item-rest correlations between the items in the pilotstudy, where we looked for the highest correlating items both within the scale as a whole, and within the specific dimensions of each scale (see Appendix 1). Item-rest correlations for

\footnotetext{
4 This Dutch translation is available upon request.

5 Due to attrition and a 'Don't know' option for most of the questions, there is some missing data.
} 
Table 2 Mean scores for the main variables of interest (standard deviation in parentheses)

\begin{tabular}{lll}
\hline & Long & Short \\
\hline ATHS (1-7) & $4.91(0.93)$ & $5.04(0.99)^{* * * *}$ \\
Agency & $4.84(1.05)$ & $5.04(1.09)^{* * * *}$ \\
Pathways & $4.98(0.95)$ & $5.03(1.06)$ \\
$\mathrm{N}$ & 259 & 996 \\
$\mathrm{HHI}(1-7)$ & $4.61(0.64)$ & $5.39(1.06)^{* * *}$ \\
Temporality & $4.63(0.69)$ & $5.47(1.11)^{* * *}$ \\
Positive readiness & $5.27(0.89)$ & $5.32(1.13)$ \\
Interconnectedness & $3.93(0.85)$ & \\
$\mathrm{N}$ & 260 & 995 \\
LOHS (1-7) & $3.98(1.25)$ & $4.42(1.20)^{* * * *}$ \\
$\quad$ Agency & $3.77(1.37)$ & $4.24(1.32)^{* * *}$ \\
Pathways & $4.20(1.24)$ & $4.60(1.21)^{* * * *}$ \\
$\mathrm{~N}$ & 258 & 995 \\
CHS (1-7) & $2.60(1.53)$ & $2.98(1.86)^{* * * *}$ \\
$\mathrm{~N}$ & 243 & 1010 \\
\hline & Long $^{\mathrm{a}}$ & Short \\
\hline $\mathrm{N}$ & 1020 & 241 \\
Life satisfaction (1-10) & $7.61(1.34)$ & $7.57(1.31)$ \\
Single item hope (1-7) & $5.04(1.33)$ & $5.11(1.19)$ \\
Positive affect (1-7) & $4.82(0.99)$ & $4.75(0.91)$ \\
Expectations (1-7) & $4.35(0.95)$ & $4.34(0.92)$ \\
Health (1-5) & $3.62(0.84)$ & $3.56(0.78)$ \\
\hline
\end{tabular}

${ }^{a}$ Long and short here refers to whether the respondent filled out one of the longer scales or filled out no longer scales at all.

the selected items all exceeded 0.70 , except for the temporality dimension of the HHI. Moreover, since the social domain of hope is already reflected in the LOHS, the Interconnectedness domain of the HHI was dropped. Additionally, the content of each of the items was investigated to see whether they were sufficiently representative of the whole scale and subscales. As a result, the final four instruments each consist of four items, with the ATHS (agency and pathways), HHI (temporality and positive readiness) and LOHS (agency and pathways) comprising two domains. The full results, including the items used in the short versions, can be found in Appendix 1.

\subsection{Main variables}

The mean scores for the short and long version of each of the scales can be found in Table 2. The significance in column two indicates whether the average scores on the short hope scales significantly differ from those on the long versions. Here, we can see that most of the differences in the mean scores of the short and long scales are statistically significantly. However, these differences are relatively small, with the largest difference on the 
Table 3 Cronbach's alpha

\begin{tabular}{lll}
\hline & Long & Short \\
\hline ATHS & 0.92 & 0.87 \\
Agency & 0.88 & 0.83 \\
Pathways & 0.85 & 0.80 \\
HHI & 0.90 & 0.90 \\
Temporality & 0.82 & 0.80 \\
Positive readiness & 0.80 & 0.84 \\
LOHS & 0.95 & 0.90 \\
Agency & 0.93 & 0.84 \\
Pathways & 0.89 & 0.80 \\
CHS & 0.97 & 0.97 \\
\hline
\end{tabular}

positive readiness domain of the $\mathrm{HHI}$ ( 0.83 difference on a 7-point scale) while all other differences are less than half a point. In general, respondents score slightly higher on the short scales compared to the long scales. Overall, the sample appears to be relatively hopeful, with scores between about a 4 and 5 on a scale of 1-7, although scores for the CHS are markedly lower than those for the other scales, with mean scores below 3. Furthermore, the sample also scores relatively high on life satisfaction (around 7.6 on a 10-point scale), a single-item hope question (a 5.0 or 5.1 on a 7 -point scale), positive affect (4.8 on a 7-point scale), expectations (4.4 and 4.3 on a 7 -point scale) and health (3.6 on a 5 -point scale).

\subsection{Parallel reliability}

Parallel reliability is calculated using pairwise correlations between scores on the short and long versions of the hope scales among the respondents that filled out the long version. All coefficients were positive, strong to moderately strong ${ }^{6}$ and significant with $99 \%$ certainty. The scores for the ATHS indicated high overlap $(0.95 * * *, 0.92 * * *$ and $0.91 * * *$ for the whole scale, agency-domain and pathways domain respectively); the HHI showed lower, but still sufficient overlap $\left(0.81^{* * *}, 0.75^{* * *}\right.$ and $0.87^{* * *}$ for the whole scale, temporality domain and positive readiness domain respectively), the LOHS showed high overlap $(0.97 * * *, 0.97 * * *$ and $0.95 * * *$ for the whole scale, agency, and pathways domains respectively) and the CHS also showed high overlap ( $\left.0.95^{* * *}\right)$.

\subsection{Internal consistency}

As can be seen in Table 3, all long and short scales showed high internal consistency, with a Cronbach's alpha over 0.8. The scores were somewhat more positive for most of the longer scales, although the differences are small. Therefore, it can be assumed that both the long and short hope scales have sufficient internal consistency, without large differences between the long and short scales.

\footnotetext{
${ }^{6}$ Here we consider correlations of 1.0 perfect, $0.9-0.7$ strong, $0.4-0.6$ moderate, $0.1-0.3$ weak, and 0 none (Dancey and Reidy 2007).
} 
Table 4 Pairwise correlations hope scales with a single item, life satisfaction, positive affect and expectations in year 3

\begin{tabular}{lllll}
\hline & Single item hope & Life satisfaction & Positive affect & Expectations \\
\hline ATHS short & $0.49^{* * *}$ & $0.45^{* * *}$ & $0.59^{* * *}$ & $0.19^{* * *}$ \\
Long version & $0.58^{* * *}$ & $0.49^{* * *}$ & $0.63^{* * *}$ & $0.20^{* * *}$ \\
HHI short & $0.60^{* * *}$ & $0.62^{* * *}$ & $0.60^{* * *}$ & $0.20^{* * *}$ \\
Long version & $0.40^{* * *}$ & $0.39^{* * *}$ & $0.53^{* * *}$ & $0.15^{* * *}$ \\
LOHS short & $0.31^{* * *}$ & $0.31^{* * *}$ & $0.27 * * *$ & $0.19^{* * *}$ \\
Long version & $0.22^{* * *}$ & $0.24 * * *$ & $0.17 * * *$ & $0.23^{* * *}$ \\
CHS short & $0.09 * * *$ & 0.04 & $0.09^{* * *}$ & $0.12^{* * *}$ \\
Long version & 0.08 & 0.03 & 0.05 & 0.05 \\
\hline
\end{tabular}

$* p<0.10 * * p<0.05 * * * p<0.01$

\subsection{Test-retest reliability}

Test-retest reliability over three waves is not particularly high, ranging between 0.57 and 0.89 , yet perhaps more importantly, the scores do not differ significantly between the long and short versions. Both the long (individual ICC of 0.67) and the short ATHS (0.68) shows moderate reliability. The long version of the HHI demonstrates moderate to high reliability (0.69), with a similar score for the short version (0.67). The LOHS scores somewhat lower, but still adequately, although the long version performs somewhat better (0.64) than the short version (0.57). The CHS is more stable, with the long version showing good reliability (0.84) and the short version moderate reliability $(0.74)$.

\subsection{Convergent validity}

As quite similar and overall positive experiences, we expect all hope scales to be positively related to a single-item hope question, life satisfaction, positive affect and expectations. However, most scales show only weak to moderate correlations with these concepts. For the ATHS, the correlations are moderate to weak, with the shorter scale scoring only slightly lower (correlation-coefficients of $0.48^{* * *}, 0.45^{* * *}, 0.59^{* * *}$ and $0.18^{* * * *}$ respectively) than the long scale $(0.58 * * *, 0.49 * * *, 0.63 * * *$ and $0.20 * * *)$. For the HHI, the pattern is reversed, with the short version more strongly related to these related concepts $(0.62 * * *, 0.62 * * *, 0.60 * * *$ and $0.22 * * *)$ than the longer version $(0.40 * * *, 0.39 * * *$, $0.53^{* * *}$ and $\left.0.15^{* * *}\right)$. Scores for the LOHS are only very weakly related, with the short version showing mainly weak, albeit positive relations $\left(0.33^{* * *}, 0.33 * * *, 0.30^{* * *}\right.$ and $0.17 * * *)$ and the long version showing correlation coefficients hardly high enough to speak of any relation $\left(0.22^{* * *}, 0.24 * * *, 0.17 * * *\right.$ and $\left.0.23 * * *\right)$. The scores are even lower and sometimes even insignificant for the CHS, both for the short $\left(0.09 * * *, 0.03,0.10^{* * *}\right.$ and $\left.0.12^{* * *}\right)$ and long version $(0.08,0.03,0.05$ and 0.05$)$. Overall, these results show that the ATHS and HHI seem to be more closely related with concepts which we would expect to be similar to a hope scale, while the LOHS and CHS perform more poorly. However, all correlations are quite low, especially considering that we would expect the single-item hope question to measure roughly the same concept as the instruments. Moreover, we find that all short scales perform roughly similar to the longer scales (see Table 4). 
Table 5 Correlation with related measures in year 3

\begin{tabular}{lllll}
\hline & ATHS & HHI & LOHS & CHS \\
\hline ATHS & - & $0.71 * * *$ & $0.39 * * *$ & $0.05^{*}$ \\
Long version & - & $0.73 * * *$ & $0.47 * * *$ & $0.16^{* *}$ \\
HHI & $0.71 * * *$ & - & $0.40^{* * *}$ & $0.15^{* * *}$ \\
Long version & $0.73 * * *$ & - & $0.32 * * *$ & $0.44 * * *$ \\
LOHS & $0.39 * * *$ & $0.40^{* * *}$ & - & $0.14 * * *$ \\
Long version & $0.23 * * *$ & $0.27 * * *$ & - & $0.22 * * *$ \\
CHS & $0.05 *$ & $0.15 * * *$ & $0.14 * * *$ & - \\
Long version & -0.07 & 0.01 & 0.07 & - \\
\hline
\end{tabular}

$* p<0.10 * * p<0.05 * * * p<0.01$

\begin{tabular}{lll}
\hline & Short & Long \\
\hline Agency & & \\
ATHS 2 & 1 & 1 \\
ATHS 4 & $0.88^{* * * *}$ & $1.01^{* * *}$ \\
ATHS 7 & & $0.83^{* * *}$ \\
ATHS 8 & & $1.05^{* * *}$ \\
Pathways & 1 & 1 \\
ATHS 1 & $1.03^{* * * *}$ & $0.87^{* * *}$ \\
ATHS 3 & & $0.85^{* * *}$ \\
ATHS 5 & & $0.92^{* * *}$ \\
ATHS 6 &
\end{tabular}

\subsection{Divergent validity}

For these instruments to show their merit, we investigated to what degree they measure unique, separate domains of a hopeful experience, or whether they all measure pretty much the same thing. Therefore, we calculated pairwise correlations between the different scales (Table 5). The ATHS appears to be relatively closely related to the HHI $(0.71 * * *$ for the short and $0.68^{* * *}$ for the long scale), but less so to the LOHS $\left(0.45^{* * *}\right.$ and $\left.0.27 * * *\right)$ and not at all to the CHS (0.04 and -0.07). Moreover, there is a moderate to weak relation between the HHI and LOHS $\left(0.46^{* * *}\right.$ for the short and $0.27 * * *$ for the long) but again hardly any relation to the CHS $\left(0.14^{* * *}\right.$ and 0.01$)$. Lastly, there is also hardly any relation between the LOHS and CHS $(0.14 * * *$ and 0.07$)$. Overall, these results show that the ATHS and HHI appear to measure quite similar, although different concepts, that the LOHS measures something somewhat similar, and the CHS is least similar to the other measures. Moreover, we see that the short version of the CHS is weakly but positively related to the others scales, whereas the longer version is not. 
Table 7 Factor loadings for the $\mathrm{HHI}$

Table 8 Factor loadings for the LOHS

\begin{tabular}{|c|c|c|c|}
\hline & & Short & Long \\
\hline \multicolumn{4}{|c|}{ Temporality and future } \\
\hline \multicolumn{2}{|l|}{ HHI 1} & 1 & 1 \\
\hline \multicolumn{2}{|l|}{ HHI 3} & $1.07 * * *$ & $0.93 * * *$ \\
\hline \multicolumn{2}{|l|}{ HHI 5} & & $0.91 * * *$ \\
\hline \multicolumn{2}{|l|}{ HHI 9} & & $-0.80 * * *$ \\
\hline \multicolumn{4}{|c|}{ Positive readiness and expectancy } \\
\hline \multicolumn{2}{|l|}{ HHI 2} & 1 & 1 \\
\hline \multicolumn{2}{|l|}{ HHI 4} & $1.95^{* * * *}$ & $1.03^{* * * *}$ \\
\hline \multicolumn{2}{|l|}{ HHI 7} & & $0.68^{* * * *}$ \\
\hline \multicolumn{2}{|l|}{ HHI 10} & & $0.50^{* * *}$ \\
\hline \multicolumn{4}{|c|}{ Interconnectedness } \\
\hline \multicolumn{2}{|c|}{ HHI 6} & & 1 \\
\hline \multicolumn{2}{|l|}{ HHI 8} & & $-0.55 * * *$ \\
\hline \multicolumn{2}{|l|}{ HHI 11} & & $-1.04 * * *$ \\
\hline \multicolumn{2}{|l|}{ HHI 12} & & -0.91 \\
\hline \multicolumn{4}{|c|}{$* p<0.10 * * p<0.05 * * * p<0.01$} \\
\hline & \multicolumn{2}{|l|}{ Short } & Long \\
\hline \multicolumn{4}{|l|}{ Agency } \\
\hline LOHS 3 & \multicolumn{2}{|l|}{1} & 1 \\
\hline LOHS 4 & \multicolumn{2}{|l|}{$0.84 * * *$} & $0.99 * * *$ \\
\hline \multicolumn{3}{|l|}{ LOHS 6} & $0.88^{* * *}$ \\
\hline \multicolumn{3}{|l|}{ LOHS 8} & $0.96 * * *$ \\
\hline \multicolumn{4}{|l|}{ Pathways } \\
\hline LOHS 1 & \multicolumn{2}{|l|}{1} & 1 \\
\hline LOHS 2 & \multicolumn{2}{|l|}{$1.10^{* * *}$} & $1.06 * * *$ \\
\hline LOHS 5 & & & $0.89^{* * *}$ \\
\hline LOHS 7 & & & $0.87 * * *$ \\
\hline
\end{tabular}

\subsection{Factor analysis}

The original ATHS, HHI and LOHS all comprise several dimensions. Here we test to what degree the shortened versions also tap into these different domains. As can be seen in Table 6, all factor loadings for both the long and short version of the ATHS are positive and significantly related to their respective domains. Moreover, the short model appears to perform somewhat better with an RMSEA below 0.08 (Browne and Cudeck 1993); TLI over 0.09 (Bentler and Bonett 1980); CFI over 0.9 (Bentler 1990); and SRMR below 0.10 (Pituch and Stevens, 2016) (specifically, RMSEA 0.07; TLI 0.99; CFI 1.00; SRMR 0.01), whereas the long model performs less well (RMSEA 0.10; TLI 0.93; CFI 0.96; SRMR $0.04)$.

Similarly, the items of both the short and long HHI relate positively to their respective domains when it comes to the domains Temporality and Positive readiness, while only two of the items of the domain Interconnectedness of the long scale are significant. Overall, 
Table 9 Hope scores in different regions

\begin{tabular}{lll}
\hline & Dutch sample & Mexican sample \\
\hline ATHS & 5.01 & 5.16 \\
Agency & 5.01 & 5.02 \\
Pathways & 5.01 & $5.30 * * *$ \\
HHI & 5.43 & $5.20 * *$ \\
Temporality & 5.55 & $5.29 * *$ \\
Positive readiness & 5.32 & 5.11 \\
LOHS & 4.29 & $4.91 * * *$ \\
Agency & 4.09 & $4.77 * * *$ \\
Pathways & 4.49 & $5.04 * * *$ \\
CHS & 2.79 & $3.72 * * *$ \\
\hline
\end{tabular}

$* \mathrm{p}<0.1, * * \mathrm{p}<0.05, * * * \mathrm{p}<0.01$ difference with scores from Dutch sample

the short scale performs somewhat better (RMSEA 0.00; TLI 1.00; CFI 1.00; SRMR 0.00) than the longer version (RMSEA 0.11; TLI 0.83; CFI 0.87; SRMR 0.07) (Table 7).

Again, for the LOHS, all items are significantly related to their respective domains, with the shorter model performing better (RMSEA 0.06; TLI 0.99; CFI 1.00; SRMR 0.01) than the longer one (RMSEA 0.24; TLI 0.99; CFI 0.85; SRMR 0.07) (Table 8).

\subsection{Hypothesis testing}

To study how well the hope instruments work in common models, fixed-effects regression models were used to estimate the relation between hope and circumstances which can be expected to relate to hope. Such a model makes use of the panel-structure of this dataset by investigating whether changes within individuals on an independent variable are related to changes in the dependent variable in the expected direction, as well as allowing us to control for time-variant changes (in this case education and employment status), leading to more robust calculations about the strength and direction of these relations.

Firstly, we expect that a change in income could be related to higher levels of hope, since a higher income allows us to make use of more resources to achieve our hopes (Pleeging et al. 2021a). However, this relation only shows up in the model using income to predict the short version of the ATHS (regression coefficient $0.17^{*}$ and $0.27^{*}$ on a scale of $1-7$ for incomes changing to between $€ 1800$ and $€ 3200$ and to over $€ 3200$ respectively). Secondly, we expect health to predict people's levels of hope, as again, good health should allow us to pursue our hopes more easily. This relation is found for the short version of the ATHS (regression coefficient $0.07 * *)$; short version of the HHI $\left(0.06^{* *}\right)$ and short version of the LOHS (0.08**). Lastly, when comparing different groups using a random-effects regression model (looking at differences between groups, rather than changes over time), we see that both the short and long version of the ATHS indicate that women are less hopeful (regression coefficients $-0.13^{* * *}$ and $-0.18^{* * *}$ respectively) whereas women actually score higher on the HHI $(0.12 * * *$ and $0.11 * *)$. Moreover, women score higher on the short LOHS $(0.09 * * *)$ and short CHS $(0.37 * * *)$, but we see no differences between women and men on the longer scales. Lastly, we see a significant, negative relation between age and hope for the short and long LOHS $\left(-1.01^{* * *}\right.$ and $\left.-1.73^{* * *}\right)$, yet a positive relation for the long ATHS $\left(0.05^{*}\right)$, short HHI $\left(0.43^{* * *}\right)$ and short CHS $\left(0.45^{*}\right)$ (see Appendix 2 for 
the full results). These results thus suggest that the hope-instruments relate differently to life circumstances such as income and health, and that not all groups of people score similarly on these instruments. Moreover, the shorter versions appear to be somewhat more sensitive to picking up of these differences.

\subsection{Cross-cultural validity}

Much hope research has been mainly conducted within western countries. To investigate whether it is likely that these hope instruments are also valid in other cultures, we examine whether there are significant differences between Dutch residents and 244 respondents currently living in Mexico (see Appendix 4 for sample descriptives). ${ }^{7}$ As can be seen in Table 9, the mean scores for some of the hope scales differs significantly between these groups. Specifically, the Mexican sample scores, on average, lower on the 'temporality' domain of the HHI, yet higher on the 'pathways' component of the ATHS, all domains of the LOHS and on the CHS.

The internal consistency is quite similar for all the scales in the two different regions. The CHS (Cronbach's alpha of 0.97 both for the Dutch and Mexican sample) scores highest, subsequently followed by the HHI ( 0.91 and 0.89 respectively) and LOHS (0.88 and 0.88), with the lowest, but still high reliability for the ATHS (0.88 and 0.83) (See full results in Appendix 4).

When it comes to the ATHS and HHI, hope scores appear to be largely similarly related to other instruments such as a single item hope question (ATHS $0.50 * * *$ for the Dutch sample, $0.56 * * *$ for the Mexican sample; HHI $0.57 * * *$ and $0.65 * * *)$, life satisfaction (ATHS $0.47^{* * *}$ and $0.63 * * *$; HHI $0.61 * * *$ and $0.70^{* * *}$ ) and positive affect (ATHS $0.64 * * *$ and $0.69 * * *$; HHI $0.60 * * *$ and $0.65 * * *)$. Scores on the LOHS are however somewhat more strongly related in Mexico when it comes to life satisfaction (LOHS $0.25^{* * *}$ and $0.48^{* * *}$ ) and positive affect (LOHS $0.27 * * *$ and $0.47 * * *$ ) but there are few differences when it comes to single item hope (LOHS $0.35^{* * *}$ and $\left.0.37 * * *\right)$ and expectations $(0.23 * * *$ and $0.37 * * *)$. Scores on the CHS appear to be more important in Mexico for all four; single item hope (CHS $0.11^{* * *}$ and $0.36^{* * *}$ ), life satisfaction (CHS 0.02 and $0.41^{* * *}$ ), positive affect (CHS $0.10^{* * *}$ and $0.31 * * *$ ) and expectations (CHS $0.12 * * *$ and $0.27 * * *$ ) are all more strongly related to the CHS in Mexico. Lastly, in their correlation to expectations, there are larger differences when it comes to the ATHS $\left(0.20^{* * *}\right.$ and $\left.0.41^{* * *}\right)$ and HHI $(0.19 * * *$ and $0.40 * * *)$.

So, overall we find that the Mexican respondents exhibit more social and spiritual hope, and that these types of hope are also more strongly related to positive states for the Mexican sample.

\section{Discussion}

Popular instruments to measure hope in academic research vary significantly in how they define hope. We assume that this does not mean that one instrument is inherently better than another, rather that each instrument has its unique merit in specific contexts, as different components of the hopeful experience become more or less important. In order to

7 For consistency, all data is from wave 2, i.e. 2019. 
aid interdisciplinary research on hope, as well as hope research in general, the current study compares and validates four short hope scales, each with a different focus, namely the ATHS (assuming hope to be mainly cognitive), the HHI (focusing more on emotion and temporality); the LOHS (assuming hope is socially constructed) and CHS (looking at the spiritual dimension of hope). We do so using three wave panel data from the Netherlands, as well as cross-sectional data from residents from Mexico. Results show that the short hope scales perform very similar to the longer scales when it comes to parallel reliability, internal consistency, test-retest reliability, and convergent and divergent reliability. Respondents score somewhat higher on the short scales compared to the long scales, yet scores are strongly correlated. All scales are internally consistent. None of the instruments is highly stable, but test-retest reliability is very similar between the short and long scales. The ATHS and HHI are more strongly related to concepts which we would expect to correlate to hope, such as a single-item hope question, life satisfaction, positive affect and expectations, while there is only a weak to moderate relation between these concepts and the LOHS and CHS. Here, again, the short and long scales perform similarly well. However, all instruments, short and long, demonstrate surprisingly low correlations to very similar instruments, such as a single-item hope question and expectations. Furthermore, each of the instruments appears to measure some unique construct, as the correlations between them is positive, but only moderate. Factor analyses indicate that the short ATHS, HHI and LOHS are at least equally well-equipped to differentiate between their domains. Hypothesis testing indicates that only the short ATHS can be predicted by changes in income, whereas a change in health predicts the short versions of the ATHS, HHI and LOHS. Also, the shorter versions of these scales pick up on differences in age and gender when it comes to hope. Lastly, although all instruments seem to work well both in the Netherlands and in Mexico, we find indications that the social and spiritual domain of hope are more important for wellbeing in Mexico. This might be a consequence of the relatively low percentage of religious residents of the Netherlands, meaning that spirituality is a less common source of hope. Moreover, social ties might play a more important role in Mexican culture, compared to the Netherlands.

This study adds to the academic literature by further studying the reliability and validity of popular hope instruments, and by developing and evaluating shorter hope scales, which can aid future (interdisciplinary) hope research. Moreover, such shorter hope scales could hopefully be more easily included in societally relevant surveys, for example within municipalities or organisations. We argue that mono-disciplinary research, which only makes use of one of these instruments, inevitably overlooks some domains of the multidimensional experience of hope as a whole, and hope that these shorter versions allow researchers to adopt a broader, more thorough perspective.

There are several limitations to this study. First, most of these results are based on cross-sectional data and pairwise correlations, without looking at causality or potential confounding variables. Although all analyses were performed in multiple years with similar results, and a fixed effects model with control variables was used to get a first glimpse into the direction and possible confounding variables in the relation between hope and several independent variables, future research using longer panels and experiments could give further insight into the causality and overlap between hope and related 
concepts. Second, although efforts were made to corroborate our findings in countries other than the Netherlands, the Mexican sample used to this effect is relatively small, and consisted of English-speaking residents, meaning that they comprise a very specific, and likely more internationally-oriented, subset of the population. Therefore, more detailed multicultural research is necessary to know whether these instruments work similarly in different cultures. Moreover, we therefore have to be careful in generalizing these results to other populations. The Dutch sample is largely representative of the Dutch population, yet does not necessarily reflect other (western) populations. The Mexican sample is not representative of the overall Mexican population. Third, this study finds surprisingly low correlations between each of the hope scales and other instruments that are expected to measure roughly the same experiences, such as a single-item hope question and expectations. Although the hope-scales thus appear to be reliable and largely valid, this might indicate that they only capture a part of the overall hopeful experience, and future research could reveal whether other additional instruments are necessary to fully explain what people experience as 'being hopeful'.

Overall, the results indicate that the short scales perform at least equally well as the existing longer scales, and that these instruments are therefore useful in investigating how hope functions in specific contexts. Moreover, we see that each of the four hope-instruments investigated here measures a different domain of the hopeful experience, but that none cover what people themselves think of hope as a whole, indicating that hope is a multidimensional concept. We would therefore recommend combining different instruments in future research if possible, and otherwise to make an informed decision about which domain of hope to focus on. Hopefully, future research using a more comprehensive measurement of hope will shed further light on the role that hope plays in our society and for us personally.

\section{Appendix 1}

Item selection.

See Tables 10, 11, 12, 13. 


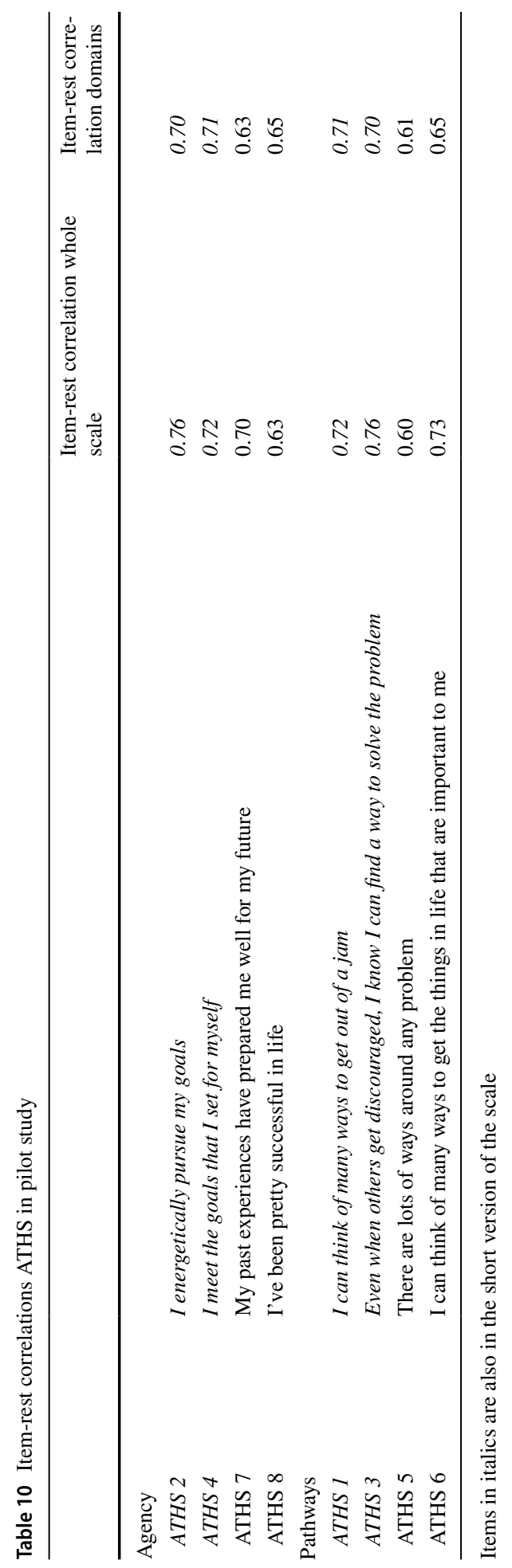


Table 11 Item-rest correlations HHI in pilot study

Item-rest correlation Item-rest correwhole scale lation domains

Temporality

HHI 1 I have a positive outlook toward life

0.70

0.55

HHI 3 I believe that each day has potential

0.69

0.53

HHI 5 I have short and/or long range goals

0.55

0.45

HHI 9

I feel scared about my future

0.39

0.40

Positive readiness

$\begin{array}{llll}\text { HHI } 2 & \text { I have a sense of direction } & 0.70 & 0.75 \\ \text { HHI } 4 & \text { I feel my life has value and worth } & 0.72 & 0.76 \\ \text { HHI } 7 & \text { I can see possibilities in the midst of difficulties } & 0.53 & 0.41 \\ \text { HHI } 10 & \text { I can recall happy/joyful times } & 0.29 & 0.27\end{array}$

Interconnectedness

$\begin{array}{llll}\text { HHI } 6 & \text { I feel all alone } & 0.42 & 0.15 \\ \text { HHI } 8 & \text { I have a faith that gives me comfort } & 0.22 & 0.19 \\ \text { HHI } 11 & \text { I have deep inner strength } & 0.51 & 0.34 \\ \text { HHI } 12 & \text { I am able to give and receive caring/love } & 0.48 & 0.31\end{array}$

Items in italics are also in the short version of the scale 


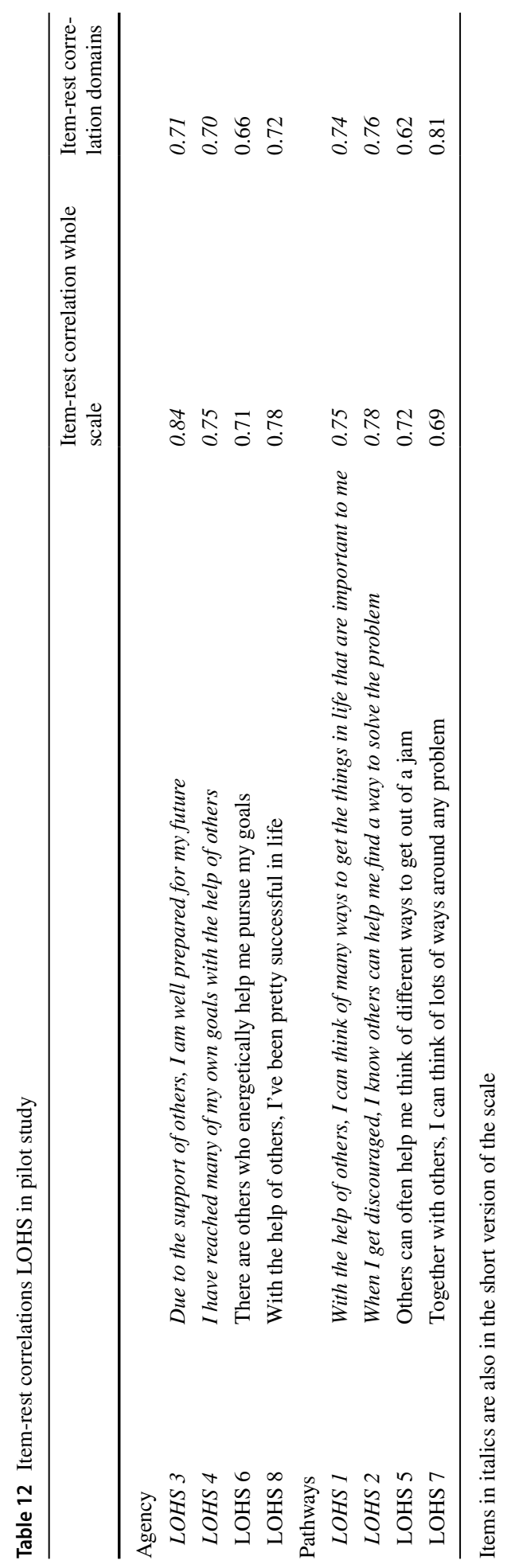


Table 13 Item-rest correlations COHS in pilot study

Item-rest correlation whole scale

COHS 1 My spiritual beliefs have empowered me to succeed in life

COHS 2 I find comfort in my spiritual beliefs

COHS 3 My spiritual beliefs keep me calm in a crisis

COHS $4 \quad$ My spiritual beliefs provide me with a feeling of safety

COHS 5 In pursuing my goals, I try to work hand-in-hand with God or a higher power

COHS 6 Accomplishments are due to human will power; not prayer or spiritual guid- $\quad-0.34$ ance

COHS 7 I believe in a benevolent higher power

COHS 8 There is a higher intelligence that guides life in a positive direction

$\begin{array}{lll}\text { COHS } 9 & \text { I believe there are ways one can get in touch with a greater spiritual force } & 0.74\end{array}$

$\begin{array}{lll}\text { COHS } 10 & \text { Spiritual experiences are possible with the right attitude } & 0.71\end{array}$

COHS 11 I have the ability to connect with God, a spiritual force or a higher power $\quad 0.81$

COHS 12 In the right environment, I can feel the presence of a spiritual force or a $\quad 0.83$ higher power

Items in italics are also in the short version of the scale 


\section{Appendix 2}

Full sample descriptives.

See Table 14.

Table 14 Demographic characteristics of the sample

\begin{tabular}{|c|c|c|c|c|}
\hline & Pilot study & Wave 1 & Wave 2 & Wave 3 \\
\hline $\mathrm{N}$ & 1623 & 903 & 868 & 1,261 \\
\hline Age (mean in years) & 52 & 52 & 55 & 55 \\
\hline \multicolumn{5}{|l|}{ Gender } \\
\hline Male & $46 \%$ & $46 \%$ & $46 \%$ & $47 \%$ \\
\hline Female & $54 \%$ & $54 \%$ & $54 \%$ & $53 \%$ \\
\hline \multicolumn{5}{|l|}{ Employment status } \\
\hline Employed & $43 \%$ & $49 \%$ & $47 \%$ & $45 \%$ \\
\hline Freelance & $6 \%$ & $8 \%$ & $2 \%$ & $7 \%$ \\
\hline Unemployed/unable to work & $8 \%$ & $28 \%$ & $28 \%$ & $31 \%$ \\
\hline Pensioned & $28 \%$ & $15 \%$ & $23 \%$ & $17 \%$ \\
\hline Other & $16 \%$ & & & \\
\hline \multicolumn{5}{|l|}{ Education } \\
\hline Lower education & $25 \%$ & $25 \%$ & $24 \%$ & $24 \%$ \\
\hline Middle education & $34 \%$ & $35 \%$ & $35 \%$ & $34 \%$ \\
\hline Higher education & $37 \%$ & $36 \%$ & $37 \%$ & $38 \%$ \\
\hline Other & $3 \%$ & $4 \%$ & $4 \%$ & $4 \%$ \\
\hline \multicolumn{5}{|l|}{ Household type } \\
\hline Single & $24 \%$ & $22 \%$ & $22 \%$ & $24 \%$ \\
\hline Partner, no children & $38 \%$ & $40 \%$ & $42 \%$ & $40 \%$ \\
\hline Partner and child(ren) & $30 \%$ & $31 \%$ & $29 \%$ & $28 \%$ \\
\hline Single with child(ren) & $4 \%$ & $5 \%$ & $4 \%$ & $5 \%$ \\
\hline Other & $3 \%$ & $2 \%$ & $3 \%$ & $3 \%$ \\
\hline \multicolumn{5}{|l|}{ Income } \\
\hline$<€ 900$ & $4 \%$ & $4 \%$ & $4 \%$ & $3 \%$ \\
\hline$€ 900-1800$ & $20 \%$ & $17 \%$ & $17 \%$ & $17 \%$ \\
\hline$€ 1800-3200$ & $36 \%$ & $34 \%$ & $34 \%$ & $35 \%$ \\
\hline$€ 3200-5000$ & $29 \%$ & $34 \%$ & $33 \%$ & $29 \%$ \\
\hline$>€ 5000$ & $10 \%$ & $12 \%$ & $13 \%$ & $16 \%$ \\
\hline \multicolumn{5}{|l|}{ Ethnicity } \\
\hline Autochthonous & $82 \%$ & $84 \%$ & $83 \%$ & $83 \%$ \\
\hline Western immigrant & $10 \%$ & $9 \%$ & $10 \%$ & $9 \%$ \\
\hline Non-western immigrant & $8 \%$ & $7 \%$ & $7 \%$ & $8 \%$ \\
\hline \multicolumn{5}{|l|}{ Long scales } \\
\hline ATHS & & $22 \%$ & $21 \%$ & $21 \%$ \\
\hline HHI & & $23 \%$ & $22 \%$ & $21 \%$ \\
\hline LOHS & & $19 \%$ & $21 \%$ & $20 \%$ \\
\hline CHS & & $13 \%$ & $19 \%$ & $19 \%$ \\
\hline No long scale & & $23 \%$ & $18 \%$ & $19 \%$ \\
\hline
\end{tabular}




\section{Appendix 3}

Hypothesis testing.

See Tables 15, 16.

Table 15 Fixed effects regression model

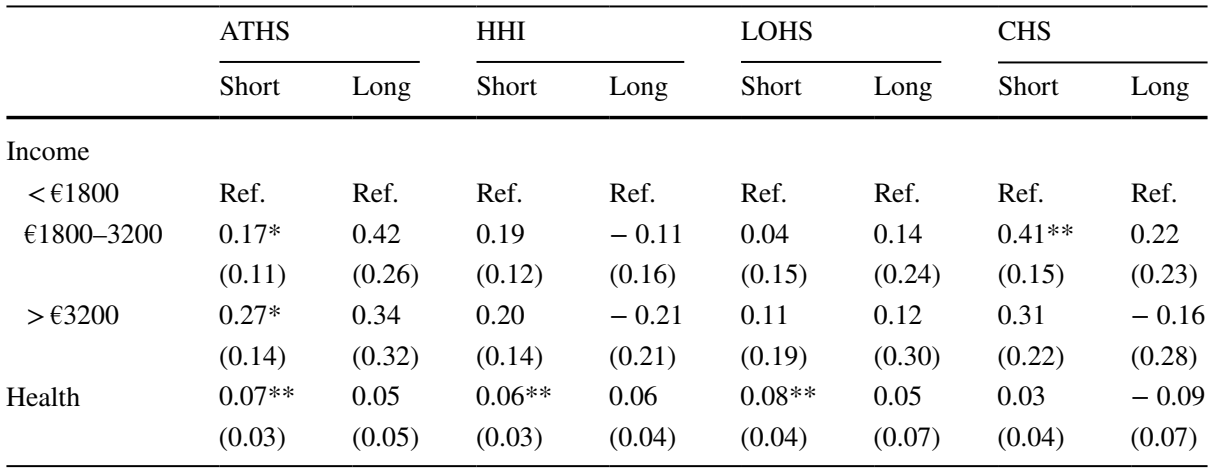

All models are controlled for education level and employment status

$* \mathrm{p}<0.1, * * \mathrm{p}<0.05, * * * \mathrm{p}<0.01$

Table 16 Random effects regression model

\begin{tabular}{|c|c|c|c|c|c|c|c|c|}
\hline & \multicolumn{2}{|l|}{ ATHS } & \multicolumn{2}{|l|}{ HHI } & \multicolumn{2}{|l|}{ LOHS } & \multicolumn{2}{|l|}{ CHS } \\
\hline & Short & Long & Short & Long & Short & Long & Short & Long \\
\hline \multicolumn{9}{|l|}{ Gender } \\
\hline Male & Ref. & Ref. & Ref. & Ref. & Ref. & Ref. & Ref. & Ref. \\
\hline Female & $\begin{array}{l}-0.13^{* * *} \\
(0.04)\end{array}$ & $\begin{array}{l}-0.18^{* * *} \\
(0.07)\end{array}$ & $\begin{array}{l}0.12 * * * \\
(0.04)\end{array}$ & $\begin{array}{l}0.11^{* *} \\
(0.05)\end{array}$ & $\begin{array}{l}0.09 * \\
(0.05)\end{array}$ & $\begin{array}{l}-0.00 \\
(0.10)\end{array}$ & $\begin{array}{l}0.28 * * * \\
(0.08)\end{array}$ & $\begin{array}{l}0.15 \\
(0.13)\end{array}$ \\
\hline Age/100 & $\begin{array}{l}0.07 \\
(0.14)\end{array}$ & $\begin{array}{l}0.05^{*} \\
(0.24)\end{array}$ & $\begin{array}{l}0.43^{* * * *} \\
(0.15)\end{array}$ & $\begin{array}{l}0.00 \\
(0.17)\end{array}$ & $\begin{array}{l}-1.03^{* * *} \\
(0.17)\end{array}$ & $\begin{array}{l}-1.73 * * * \\
(0.33)\end{array}$ & $\begin{array}{l}0.45^{*} \\
(0.25)\end{array}$ & $\begin{array}{l}0.56 \\
(0.42)\end{array}$ \\
\hline
\end{tabular}

All models are controlled for education level and employment status

$* \mathrm{p}<0.1, * * \mathrm{p}<0.05, * * * \mathrm{p}<0.01$

\section{Appendix 4}

Cross-cultural validity.

See Tables 17, 18, 19, 20, 21, 22. 
Table 17 Demographic characteristics of the sample from Mexico

\begin{tabular}{lc}
\hline & Mexico \\
\hline $\mathrm{N}$ & 244 \\
Age (mean in years) & 28 \\
Gender & \\
Male & $61 \%$ \\
Female & $38 \%$ \\
Employment status & \\
Employed & $43 \%$ \\
Freelance & $19 \%$ \\
Unemployed/unable to work & $10 \%$ \\
Pensioned & $4 \%$ \\
Other & $27 \%$ \\
Household type & \\
Single & $20 \%$ \\
Partner, no children & $3 \%$ \\
Partner and child(ren) & $17 \%$ \\
Single with child(ren) & $28 \%$ \\
Other & $32 \%$ \\
Income & \\
$<€ 900$ & $32 \%$ \\
$€ 900-1800$ & $33 \%$ \\
$€ 1800-3200$ & $21 \%$ \\
$€ 3200-5000$ & $7 \%$ \\
$>€ 5000$ & \\
\hline & \\
\hline & \\
\hline & \\
\hline & \\
\hline & \\
\hline & \\
\hline
\end{tabular}

\begin{tabular}{lll}
\hline & Dutch sample & Mexican sample \\
\hline ATHS & 0.88 & 0.83 \\
Agency & 0.81 & 0.76 \\
Pathways & 0.81 & 0.68 \\
HHI & 0.91 & 0.89 \\
Temporality & 0.82 & 0.78 \\
Positive readiness & 0.86 & 0.82 \\
LOHS & 0.88 & 0.88 \\
Agency & 0.83 & 0.84 \\
Pathways & 0.77 & 0.75 \\
CHS & 0.97 & 0.97 \\
\hline
\end{tabular}


Table 19 Correlation hope scales and a single item hope question

Table 20 Correlation hope scales and life satisfaction

Table 21 Correlation hope scales and positive affect

\begin{tabular}{lll}
\hline & $\begin{array}{l}\text { Dutch autochtho- } \\
\text { nous }\end{array}$ & Mexican sample \\
\hline ATHS & $0.50^{* * *}$ & $0.56 * * *$ \\
Agency & $0.48^{* * *}$ & $0.57 * * *$ \\
Pathways & $0.44 * * *$ & $0.46 * * *$ \\
HHI & $0.57 * * *$ & $0.65 * * *$ \\
Temporality & $0.55^{* * *}$ & $0.64 * * *$ \\
Positive readiness & $0.54 * * *$ & $0.59 * * *$ \\
LOHS & $0.35 * * *$ & $0.37 * * *$ \\
Agency & $0.29 * * *$ & $0.32 * * *$ \\
Pathways & $0.38 * * *$ & $0.38 * * *$ \\
CHS & $0.11 * * *$ & $0.36 * * *$ \\
\hline
\end{tabular}

$* p<0.10 * * p<0.05 * * * p<0.01$

\begin{tabular}{lll}
\hline & $\begin{array}{l}\text { Dutch autochtho- } \\
\text { nous }\end{array}$ & Mexican sample \\
\hline ATHS & $0.47 * * *$ & $0.63 * * *$ \\
Agency & $0.47 * * *$ & $0.67 * * *$ \\
Pathways & $0.41 * * *$ & $0.49 * * *$ \\
HHI & $0.61 * * *$ & $0.70 * * *$ \\
Temporality & $0.57 * * *$ & $0.64 * * *$ \\
Positive readiness & $0.58 * * *$ & $0.68 * * *$ \\
LOHS & $0.25 * * *$ & $0.48 * * *$ \\
Agency & $0.22^{* * *}$ & $0.47 * * *$ \\
Pathways & $0.25 * * *$ & $0.44 * * *$ \\
CHS & 0.02 & $0.41 * * *$ \\
\hline
\end{tabular}

$* p<0.10 * * p<0.05 * * * p<0.01$

\begin{tabular}{lll}
\hline & $\begin{array}{l}\text { Dutch autochtho- } \\
\text { nous }\end{array}$ & Mexican sample \\
\hline ATHS & $0.64 * * *$ & $0.69 * * *$ \\
Agency & $0.63 * * *$ & $0.69 * * *$ \\
Pathways & $0.57 * * *$ & $0.57 * * *$ \\
HHI & $0.60 * * *$ & $0.65 * * *$ \\
Temporality & $0.58 * * *$ & $0.63 * * *$ \\
Positive readiness & $0.57 * * *$ & $0.60 * * *$ \\
LOHS & $0.27 * * *$ & $0.47 * * *$ \\
Agency & $0.20 * * *$ & $0.40 * * *$ \\
Pathways & $0.31 * * *$ & $0.49 * * *$ \\
CHS & $0.10 * * *$ & $0.31 * * *$ \\
\hline
\end{tabular}

$* p<0.10 * * p<0.05 * * * p<0.01$ 
Table 22 Correlation hope scales and expectations

\begin{tabular}{lll}
\hline & $\begin{array}{l}\text { Dutch autochtho- } \\
\text { nous }\end{array}$ & Mexican sample \\
\hline ATHS & $0.20 * * *$ & $0.41 * * *$ \\
Agency & $0.19 * * *$ & $0.44 * * *$ \\
Pathways & $0.18^{* * *}$ & $0.31 * * *$ \\
HHI & $0.19 * * *$ & $0.39 * * *$ \\
Temporality & $0.16 * * *$ & $0.34 * * *$ \\
Positive readiness & $0.19 * * *$ & $0.40 * * *$ \\
LOHS & $0.23 * * *$ & $0.30 * * *$ \\
Agency & $0.22 * * *$ & $0.28 * * *$ \\
Pathways & $0.21 * * *$ & $0.28 * * *$ \\
CHS & $0.12 * * *$ & $0.27 * * *$ \\
\hline
\end{tabular}

$* p<0.10 * * p<0.05 * * * p<0.01$

Acknowledgements Emma Pleeging received financial support from the Goldschmeding Foundation for People, Work and Economy (project 'Hope as an incentive'). This research was not preregistered with an independent, institutional registry. Respondents are participants of the LISSpanel (Longitudinal Internet Studies for the Social sciences). Respondents provided consent to use their responses for this study. All individual participants were informed about the purpose and duration of the survey, that their answers were anonymous and that their participation was voluntary.

Data availability This research was not preregistered with an independent, institutional registry, since participants of the LISS panel did not need to agree to this before the study.

Code availability A STATA do file is available upon request.

\section{Declarations}

Conflict of interest Funding organization had no influence on the content of this work. The author has no further conflicts of interest to declare.

Consent to participate Respondents are participants of the LISSpanel (Longitudinal Internet Studies for the Social sciences). Respondents provided consent to use their responses for this study. All individual participants were informed about the purpose and duration of the survey, that their answers were anonymous and that their participation was voluntary.

Open Access This article is licensed under a Creative Commons Attribution 4.0 International License, which permits use, sharing, adaptation, distribution and reproduction in any medium or format, as long as you give appropriate credit to the original author(s) and the source, provide a link to the Creative Commons licence, and indicate if changes were made. The images or other third party material in this article are included in the article's Creative Commons licence, unless indicated otherwise in a credit line to the material. If material is not included in the article's Creative Commons licence and your intended use is not permitted by statutory regulation or exceeds the permitted use, you will need to obtain permission directly from the copyright holder. To view a copy of this licence, visit http://creativecommons.org/licenses/by/4.0/.

\section{References}

Aspinwall, L.G., Leaf, S.L.: In search of the unique aspects of hope: pinning our hopes on positive emotions, future-oriented thinking, hard times, and other people. Psychol. Inq. 13(4), 276-321 (2002) 
Bailey, T.C., Eng, W., Frisch, M.B., Snyder, C.R.: Hope and optimism as related to life satisfaction. J. Posit. Psychol. 2(3), 168-175 (2007)

Bentler, P.M.: Comparative fit indexes in structural models. Psychol. Bull. 107, 238-246 (1990)

Bentler, P.M., Bonett, D.G.: Significance tests and goodness of fit in the analysis of covariance structures. Psychol. Bull. 88, 588-606 (1980)

Bernardo, A.B.: Extending hope theory: internal and external locus of trait hope. Personality Individ. Differ. 49(8), 944-949 (2010)

Browne, M.W., Cudeck, R.: Alternative ways of assessing model fit. In: Bollen, K.A., Long, J.S. (eds.) Testing structural equation models, pp. 136-162. Sage, Newbury Park (1993)

Cheung, F., Lucas, R.E.: Assessing the validity of single-item life satisfaction measures: results from three large samples. Qual. Life Res. 23(10), 2809-2818 (2014)

Dancey, C.P., Reidy, J.: Statistics without maths for psychology. Pearson Education, Harlow (2007)

Day, J.P.: Hope. Am. Philos. q. 6(2), 89-102 (1969)

Du, H., King, R.B.: Placing hope in self and others: exploring the relationships among self-construals, locus of hope, and adjustment. Personality Individ. Differ. 54(3), 332-337 (2013)

Duflo, E. (2012). Lack of hope and the persistence of poverty. Marshall Lecture Series

Flechtner, S.: Aspiration traps: when poverty stifles hope. Inequal. Focus 2(4), 1-4 (2014)

Fredrickson, B.L.: Positive emotions broaden and build. Adv. Exp. Soc. Psychol. 47, 1-53 (2013)

Graham, C., Pinto, S.: Unequal hopes and lives in the USA: optimism, race, place, and premature mortality. J. Popul. Econ. 32(2), 665-733 (2019)

Herth, K.: Abbreviated instrument to measure hope: development and psychometric evaluation. J. Adv. Nurs. 17, 1251-1259 (1992)

Howell, A.J., Bailie, T., Buro, K.: Evidence for vicarious hope and vicarious gratitude. J. Happiness Stud. 16(3), 687-704 (2015)

Krafft, A.M., Walker, A.M.: Exploring the concept and experience of hope-theoretical and methodological foundations. In: Krafft, A., Perrig-Chiello, P., Walker, A. (eds.) Hope for a good life. Social indicators research series, vol. 72, pp. 3-19. Springer, Cham (2018)

Ludema, J.D., Wilmot, T.B., Srivastva, S.: Organizational hope: reaffirming the constructive task of social and organizational inquiry. Human Relations 50(8), 1015-1052 (1997)

Lybbert, T.J., Wydick, B.: Poverty, aspirations, and the economics of hope. Econ. Dev. Cult. Change 66(4), 709-753 (2018)

Marcel, G.: Homo viator: introduction to a metaphysic of hope. Harper \& Row, New York (1962)

Martin, A.M.: Hopes and dreams. Philos. Phenomenol. Res. LXXXII I(1), 148-173 (2011)

O'Connor, K.J., Graham, C.: Longer, more optimistic, lives: historic optimism and life expectancy in the United States. J. Econ. Behav. Organ. 168, 374-392 (2019)

Ojala, M.: Hope and climate change: the importance of hope for environmental engagement among young people. Environ. Educ. Res. 18(5), 625-642 (2012)

Pituch, K.A., Stevens, J.P.: Applied multivariate statistics for the social sciences, 6th edn. New York, Routledge (2016)

Pleeging, E., van Exel, J., Burger, M.J., Stavropoulos, S.: Hope for the future and willingness to pay for sustainable energy. Ecol. Econ. 1811, 106900 (2020)

Pleeging, E., Burger, M., van Exel, J.: Hope mediates the relation between income and subjective wellbeing. J. Happiness Stud. 22, 2075-2102 (2021a)

Pleeging, E., van Exel, J., Burger, M.: Characterizing hope: an interdisciplinary overview of the characteristics of hope. Appl. Res. Qual. Life (2021b). https://doi.org/10.1007/s11482-021-09967-x

Rand, K.L., Cheavens, J.S.: Hope theory. In: Lopez, S.J., Snyder, C.R. (eds.) The Oxford handbook of positive psychology, 2nd edn. Oxford University Press, Oxford (2009)

Redlich-Amirav, D., Ansell, L.J., Harrison, M., Norrena, K.L., Armijo-Olivo, S.: Psychometric properties of hope scales: a systematic review. Int. J. Clin. Prac. 72(7), e13213 (2018)

Reichard, R.J., Avey, J.B., Lopez, S., Dollwet, M.: Having the will and finding the way: a review and metaanalysis of hope at work. J. Posit. Psychol. 8(4), 292-304 (2013)

Scioli, A., Ricci, M., Nyugen, T., Scioli, E.R.: Hope: its nature and measurement. Psychol. Relig. Spiritual. 3(2), 78-97 (2011)

Snyder, C.R.: Hope theory: rainbows in the mind. Psychol. Inq. 13(4), 249-275 (2002)

Snyder, C.R., Harris, C., Anderson, J.R., Holleran, S.A., Irving, L.M., Sigmon, S.T., Yoshinobu, L., Gibb, J., Langelle, C., Harney, P.: The will and the ways: development and validation of an individual-differences measure of hope. J. Pers. Soc. Psychol. 60(4), 570-585 (1991)

Van den Heuvel, S.: Historical and multidisciplinary perspectives on hope. Springer International Publishing, Cham (2020) 
Watson, D., Clark, L.A., Tellegen, A.: Development and validation of brief measures of positive and negative affect: the PANAS scales. J. Pers. Soc. Psychol. 54(6), 1063-1070 (1988)

Webb, D.: Modes of hoping. Hist. Hum. Sci. 20(3), 65-83 (2007)

Publisher's Note Springer Nature remains neutral with regard to jurisdictional claims in published maps and institutional affiliations. 